\title{
Early versus delayed flow diversion for ruptured intracranial aneurysms: A meta-analysis
}

\author{
Rimal Hanif Dossani \\ Louisiana State University Health Sciences Center, Louisiana, USA. \\ Devi P. Patra \\ Louisiana State University Health Sciences Center, Louisiana, USA. \\ Jennifer Kosty \\ Louisiana State University Health Sciences Center, Louisiana, USA. \\ Fareed Jumah \\ Louisiana State University Health Sciences Center, Louisiana, USA. \\ Okkes Kuybu \\ Louisiana State University Health Sciences Center, Louisiana, USA.
}

See next page for additional authors

Follow this and additional works at: https://ecommons.aku.edu/pakistan_fhs_mc_surg_neurosurg

Part of the Neurology Commons, Neurosurgery Commons, and the Surgery Commons

\section{Recommended Citation}

Dossani, R., Patra, D., Kosty, J., Jumah, F., Kuybu, O., Mohammed, N., Waqas, M., Riaz, M., Cuellar, H. (2019). Early versus delayed flow diversion for ruptured intracranial aneurysms: A meta-analysis. World Neurosurgery, 126, 41-52.

Available at: https://ecommons.aku.edu/pakistan_fhs_mc_surg_neurosurg/179 


\section{Authors}

Rimal Hanif Dossani, Devi P. Patra, Jennifer Kosty, Fareed Jumah, Okkes Kuybu, Nasser Mohammed, Muhammad Waqas, Muhammad Riaz, and Hugo Cuellar 


\section{Accepted Manuscript}

Early versus delayed flow diversion for ruptured intracranial aneurysms: A metaanalysis

Rimal Hanif Dossani, M.D., Devi P. Patra, M.D., Jennifer Kosty, M.D., Fareed Jumah, M.D., Okkes Kuybu, M.D., Nasser Mohammed, M.D., Muhammad Waqas, M.B.B.S.,

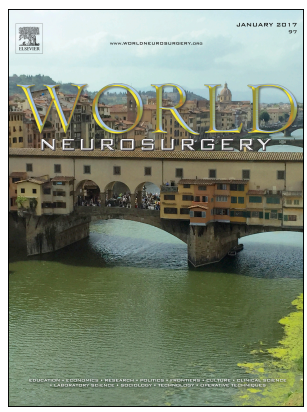
Muhammad Riaz, M.B.B.S., Hugo Cuellar, M.D., Ph.D.

PII: S1878-8750(19)30455-3

DOI: https://doi.org/10.1016/j.wneu.2019.02.044

Reference: WNEU 11517

To appear in: World Neurosurgery

Received Date: 29 December 2018

Revised Date: 3 February 2019

Accepted Date: 5 February 2019

Please cite this article as: Dossani RH, Patra DP, Kosty J, Jumah F, Kuybu O, Mohammed N, Waqas M, Riaz M, Cuellar H, Early versus delayed flow diversion for ruptured intracranial aneurysms: A metaanalysis, World Neurosurgery (2019), doi: https://doi.org/10.1016/j.wneu.2019.02.044.

This is a PDF file of an unedited manuscript that has been accepted for publication. As a service to our customers we are providing this early version of the manuscript. The manuscript will undergo copyediting, typesetting, and review of the resulting proof before it is published in its final form. Please note that during the production process errors may be discovered which could affect the content, and all legal disclaimers that apply to the journal pertain. 
Title:

Early versus delayed flow diversion for ruptured intracranial aneurysms: A meta-analysis

Authors:

Rimal Hanif Dossani, M.D. ${ }^{1}$, Devi P. Patra, M.D. ${ }^{1}$, Jennifer Kosty, M.D. ${ }^{1}$, Fareed Jumah, M.D. ${ }^{1}$, Okkes Kuybu, M.D. ${ }^{2}$, Nasser Mohammed, M.D. ${ }^{1}$, Muhammad Waqas, M.B.B.S. ${ }^{3}$, Muhammad Riaz, M.B.B.S. ${ }^{3}, \&$ Hugo Cuellar, M.D., Ph.D. ${ }^{1}$

${ }^{1}$ Department of Neurosurgery

Louisiana State University Health Sciences Center

Shreveport, LA

${ }^{2}$ Department of Neurology

Louisiana State University Health Sciences Center

Shreveport, LA

${ }^{3}$ Section of Neurosurgery

The Aga Khan University Hospital

Karachi, Pakistan

Corresponding author:

Rimal H. Dossani, M.D.

Department of Neurosurgery

PO BOX 33932

1501 King's Highway

Shreveport, LA 71130-3932

Phone: (954) 682-2168

Fax: (318) 675-6867

Email: rimalh@gmail.com

Running Title:

Early vs. delayed flow diversion for ruptured intracranial aneurysms

Keywords: flow diversion, ruptured aneurysm, subarachnoid hemorrhage

Conflict of Interest: None

Disclosure of Funding: None 


\begin{abstract}
Objective: The use and timing of flow diversion for aneurysmal subarachnoid hemorrhage (SAH) is controversial. The objective of this study is to perform a meta-analysis and systematic review to compare overall complication rate between early versus delayed flow diversion for ruptured aneurysms.
\end{abstract}

Methods: Literature search for all eligible articles was performed using PubMed, Cochrane and Web of Science databases. The primary outcome was the overall complication rate (any complication in the perioperative period), and secondary outcomes were (1) hemorrhage and (2) stroke/death (all hemorrhagic/ischemic strokes and/or death).

Results: Thirteen articles including 142 patients met inclusion criteria. Eighty-nine $(62.7 \%)$ patients underwent early deployment of flow diverters (i.e., 2 days or less). The odds ratio for overall complication rate with early versus delayed flow diversion was 0.95 (95\% CI=0.36-2.49, $\mathrm{p}=0.42)$. The odds ratio for the secondary outcome of hemorrhagic complication for early vs. delayed flow diversion was 1.44 (95\% CI 0.454.52, $\mathrm{p}=0.87$ ) and of stroke/death was 1.67 (95\% CI 0.5-4.9, $\mathrm{p}=0.69)$. The odds ratio of early vs. delayed flow diversion for blister/dissecting/fusiform aneurysms was 0.82 (95\% CI 0.29-2.30) and for saccular/giant aneurysms was 2.23 (95\% CI 0.17-29.4). At last follow-up, $71.6 \%$ of patients had good performance status (mRS score 0-2), and the rate of angiographic aneurysm occlusion was $90.2 \%$.

Conclusion: This meta-analysis did not show a difference in overall complication rate between early vs. delayed flow diversion for ruptured aneurysms. Early flow diversion for ruptured blister/fusiform/dissecting aneurysms carries a lower risk of aneurysm rerupture and overall complications as compared to that for ruptured saccular/giant aneurysms.

Keywords: flow diversion, ruptured aneurysm, subarachnoid hemorrhage 


\section{INTRODUCTION}

Subarachnoid hemorrhage (SAH) from a ruptured intracranial aneurysm occurs with an incidence of 6-8 per 100,000 in the western population. ${ }^{1-3}$ The International Subarachnoid Aneurysm Trial (ISAT) ${ }^{1}$ and the Barrow Ruptured Aneurysm Trial (BRAT) ${ }^{4}$ provided Level 1 evidence for the safety and efficacy of both endovascular coiling and neurosurgical clipping. Some types of aneurysm morphologies-including giant, dissecting, fusiform and blister-are considered "challenging" because they are difficult to treat by conventional endovascular or neurosurgical means. For example, neurosurgical treatment of a fusiform aneurysm may require trapping and bypass, which carries inherent morbidity. Similarly, endovascular treatment of a blister aneurysm may not be amenable to primary coiling and may require stent or balloon assistance.

In recent years, flow diversion has emerged as a viable endovascular treatment option for unruptured aneurysms with "challenging" morphologies. ${ }^{5,6}$ Flow diversion obviates the need for neurosurgical bypass by placing a stent with high metal coverage across the aneurysmal segment of an intracranial vessel. ${ }^{7}$ Stasis of blood flow within the aneurysm sac leads to aneurysm thrombosis. ${ }^{8}$ Over time, neointimal proliferation incorporates the stent within the vessel's endothelium and removes the aneurysm from the circulation. ${ }^{9}$

The use of flow diversion for ruptured aneurysms, unlike that for unruptured aneurysms, is controversial and has two main concerns. ${ }^{10}$ First, to prevent thromboembolic complications, flow-diverting stents require antiplatelet medications, which may exacerbate bleeding in SAH and increase the risk of hemorrhagic complications from additional procedures (such as ventriculostomy to relieve hydrocephalus). ${ }^{11}$ Second, flow diversion results in delayed aneurysm occlusion, which may increase the risk of aneurysm rerupture in the acute phase of SAH. ${ }^{12}$ Despite these concerns, a number of retrospective case series have presented their experience with flow diversion to treat ruptured aneurysms with "challenging" morphologies. ${ }^{13-23}$ These case series have justified the use of flow diversion as a salvage treatment for ruptured aneurysms with "challenging" morphologies, which are difficult to treat by traditional neurosurgical or endovascular modalities. ${ }^{23,24}$

Once a decision is made to treat a ruptured aneurysm with flow diversion, there is considerable debate on the ideal timing of flow diverter placement. Some experts recommend early flow 
diversion (less than 2 days from SAH ictus), ${ }^{19,21,25}$ while others advocate for delayed treatment (2-14 days from SAH ictus). ${ }^{18,26}$ The stated reasons for timing of flow diversion are anecdotal; for example, some prefer early flow diversion because it may facilitate faster patient rehabilitation, while others prefer delayed flow diversion because it may minimize hemorrhagic complications from dual antiplatelet therapy. However, there are no published data comparing the safety profile of early versus delayed flow diversion for ruptured aneurysms. Therefore, the current study presents results from a meta-analysis comparing the overall complications associated with early vs. delayed flow diversion for ruptured aneurysms. 


\section{METHODS}

A systematic review and meta-analysis was performed to compare the complication rates associated with early vs. delayed flow-diverter treatment of ruptured intracranial aneurysms. The Preferred Reporting Items for Systematic Reviews and Meta-analysis (PRISMA) ${ }^{27}$ protocol was followed to perform the literature search, to determine the inclusion and exclusion criteria, and to select the appropriate statistical methods.

\section{Literature search}

A detailed literature search was performed from three electronic databases-PubMed, Cochrane Library and the Web of Science-from January 2010 to February 2018. All published articles and abstracts were searched in both English and non-English languages using the key terms “flow diverter", "pipeline”, "stent", “aneurysms", "ruptured”, "subarachnoid hemorrhage” and their synonyms using [AND] and/or [OR] connectors. An Internet search was also performed to look for any unpublished literature. Three investigators (RHD, DPP, RM) independently performed the primary search, reviewed the titles of the articles, and removed duplicated articles. Then, the full text of each article reviewed by two investigators (RHD, RM) to identify suitable studies to be included in the analysis. Any discrepancy in selection of studies and data collection was clarified by mutual consensus.

\section{Inclusion and exclusion criteria}

All studies describing outcomes after flow-diverter treatment of ruptured aneurysms were reviewed. Case reports and case series with fewer than 5 patients were excluded. The most important inclusion criteria was the notation of exact timing (in days) of flow-diverter treatment following subarachnoid hemorrhage. Other inclusion criteria included mention of morbidity (procedural, hemorrhagic, or ischemic complications) and mortality. Studies describing flow diversion as a staged procedure (for example, after initial coiling of ruptured aneurysm) were excluded. Studies with overlapping cohorts of patients were screened, and the latest published article or the article with higher number of patients was selected. Age, race, country of origin were not factors for exclusion. Corresponding authors were contacted by email and phone to account for missing data in eligible manuscripts. 


\section{Outcome measures and definitions}

Timing of flow-diverter treatment was categorized as "Early" if it occurred within the first 2 days following SAH or "Delayed" if it was more than 2 days. The primary outcome was the "Overall complication rate," which included any complication in the perioperative period. Secondary outcomes were "Stroke/Death," which included all hemorrhagic/ischemic strokes and/or death, and "Hemorrhage," which included only hemorrhagic strokes. Multiple predictive factors were correlated with the primary outcome, including the age of the patient ( $\leq 60$ years vs. $>60$ years), aneurysm type (blister/dissecting/fusiform vs saccular/giant) and aneurysm location (anterior vs. posterior circulation).

\section{Assessment of study quality, bias and study heterogeneity}

Two reviewers independently reviewed the full text of each article to eliminate selection bias. Study quality was evaluated using the Quality Assessment Tool for case series studies from the National Heart, Lung, and Blood Institute (NHLBI), which comprises 9 criteria/questions. ${ }^{28} \mathrm{~A}$ study was considered to be of good quality if it met at least 7 of the 9 criteria, "fair" if it met 46 criteria, and "poor" if met 3 or less . Publication bias for the primary and secondary outcome was evaluated using Funnel plots, and the significance of asymmetry along with tests for small study effects (H0) was assessed with Eggers test using mixed effects meta-regression model. Study heterogeneity was evaluated with Cochran Q test and I2.

\section{Statistical methods}

1. Individual Participant Data (IPD) Meta-analysis

We implemented the Individual Participant Data (IPD) meta-analysis ${ }^{29}$ to review both the primary and secondary outcomes of individual patients in early vs. delayed treatment groups in each of the included studies. In IPD meta-analysis, individual patient data is pooled while preserving the clustering of patients within each study. In comparison to traditional metaanalysis, IPD meta-analysis allows both study-level and patient-level interactions. ${ }^{29}$ For example, in this study, the IPD meta-analysis allowed us to perform subgroup analyses for overall complications in the early vs. delayed treatment groups based on patient age, and location and type of aneurysm. 
We performed a two-staged IPD meta-analysis using the "IPDMETAN" module in the STATA software (Statacorp, USA, version 15.1) using the collapse-based syntax. Pooled estimates of odds ratios with 95 percent confidence interval were calculated using Mantel-Haenszel method for both the primary and secondary outcomes. A fixed model was used due to low level of heterogeneity among the studies. Forest plots were created to combine data from all included studies and to calculate a pooled summary of all data. L'Abbé plots were drawn to observe the complication risks with early vs. delayed treatment and to explore the heterogeneity of effect estimates within the meta-analysis using the STATA module "METAN". Subgroup analysis with meta-regression was conducted from the summary estimates to identify potential moderators of overall complication rate with a restricted maximum likelihood estimator of the variance of the true effect. The moderators that were analyzed to affect the variability in effect sizes included the patient label characteristics like age, location and type of aneurysm.

\section{Proportion Meta-Analysis}

A limitation of the IPD meta-analysis in this review was the small number of studies (7) including patients in both early and delayed treatment cohorts. Of the 13 studies meeting inclusion criteria, 6 studies were not included in the IPD meta-analysis because all patients in each of these 6 studies received either early or delayed flow-diverter treatment. Therefore, to overcome this limitation, we additionally performed a meta-analysis of proportions ${ }^{30}$ by pooling patients in the early vs. delayed treatment groups. This meta-analysis of proportions allowed us to increase the sample size and to calculate odds ratios with increased power.

The meta-analysis of proportions was performed using the METAPROP module of STATA software (Statacorp, USA, version 15.1). ${ }^{30}$ A fixed model was used to calculate the pooled estimates after Freeman-Tukey Double Arcsine Transformation to stabilize the variances. Metaregression analysis was performed to compare the estimates between early vs. delayed treatment groups. 


\section{RESULTS}

\section{Study characteristics}

The initial database search identified 1482 articles after accounting for duplicate titles. Full texts of 55 articles were reviewed for eligibility. Finally, 13 articles ${ }^{13,14,17-26,31}$ meeting inclusion criteria were selected for data archival and analysis. Individual patient data was retrieved from each of the 13 studies. Seven studies were included in the Individual Participant Data (IPD) meta-analysis because these studies had patients with complications in both the early and delayed treatment groups, and were therefore directly comparable to each other. To account for limitations in the IPD meta-analysis, a traditional Proportion meta-analysis was also performed, which included all 13 studies. The details of the (Preferred Reporting Items for Systematic Reviews and Meta-analysis) PRISMA protocol are depicted in Figure 1.

\section{Patient characteristics}

Summary characteristics for each of the 13 included studies are listed in Table 1 . The number of patients included from each study ranged from 5 to 18, for a combined total of 142 patients. The mean patient age was 53.7 years. The timing of intervention from presentation with SAH to flow diversion was early ( 2 days or less) in $89(62.7 \%)$ patients and delayed in 53 (37.3\%), with an average time to treatment of 4.2 days (range 3-26days). The mean aneurysm size was $6 \mathrm{~mm}$. The vast majority of patients $(117 / 142,82.3 \%)$ with SAH treated with flow diversion had ruptured fusiform $(12 / 142,8.5 \%)$, dissecting $(46 / 142,32.4 \%)$ or blister $(59 / 142,41.5 \%)$ aneurysms, which are not amenable to coil placement. As a result, adjunctive coiling along with flow diversion was used in a minority of patients $(16 / 142,11.3 \%)$. Aneurysms treated with flow diversion were located in the anterior circulation in $60.6 \%(86 / 142)$ of patients, and were located in the posterior circulation in $39.4 \%(56 / 142)$. In the majority of studies $(n=9)$, the pre-procedure antiplatelet regimen of choice was $600 \mathrm{mg}$ clopidogrel and $300 \mathrm{mg} / 625 \mathrm{mg}$ aspirin. Pipeline embolization device (PED; Medtronic, Irvine, California, USA) was the only flow diverter used in 10 studies, SILK flow diverter (SFD; Balt Extrusion, Montmorency, France) was the only flow diverter used in 2 studies, and one study used PED, SFD and Surpass (Surpass; Stryker Neurovascular, Fremont, California, USA) flow diverters (Table 1). The demographic and 
clinical characteristics of the patients in the early and delayed treatment groups have been summarized in Table 2.

\section{Complications}

None of the aneurysms reruptured prior to treatment with flow diversion. Aneurysm rerupture occurred in 5 patients (3.5\%), and the mortality rate for these 5 patients was $100 \%$. The aneurysm size was larger than $2 \mathrm{~cm}$ in $60 \%$ (3/5) of reruptured aneurysms. In the entire patient series, the rerupture rate of all aneurysms larger than $2 \mathrm{~cm}$ was $42.9 \%(3 / 7)$, while the rerupture rate of all aneurysms smaller than $2 \mathrm{~cm}$ was $1.9 \%$ (2/107). The morphology of reruptured aneurysms was saccular in 40\% (2/5) and fusiform in 60\% (3/5). Aneurysms that reruptured were treated during the early phase in $100 \%(5 / 5)$ of cases. In $60 \%$ of cases $(3 / 5)$, the aneurysm reruptured intraoperatively during or immediately following deployment of flow diverter; the other 2 reruptures occurred on post-procedure day 1 and 8 . Adjunctive coiling along with flow diversion was utilized to treat only one of these ruptured aneurysms $(20 \%, 1 / 5)$. The rate of aneurysm rerupture with flow diversion alone was $3.3 \%$ (4/122) and with flow diversion + adjunctive coiling was $5.6 \%(1 / 18)$.

Hemorrhagic complications other than aneurysm rerupture occurred in $12 \%$ of patients (17/142), 5 of which led to mortality. Of these hemorrhagic complications, 6 occurred from placement of an external ventricular drain (EVD), and other hemorrhages occurred in disparate locations, including spinal epidural hematoma (1), vitreous hemorrhage (1), worsening intraventricular hemorrhage (1), hemorrhagic infarct (2), cerebellar hematoma (1), frontal intraparenchymal hematoma (1), among others. Ischemic complications occurred in 7\% (10/142) of cases, 2 of which led to mortality (brainstem ischemia and large middle cerebral artery infarction). Procedure-related complications occurred in 17 patients (12\%).

The overall mortality rate was $15.5 \%$ (22/142), and the overall complication rate was $27.5 \%$ (39/142).

\section{Clinical and angiographic outcomes}


The overall percentage of patients with good performance status (mRS score of 0-2) following flow diversion for ruptured aneurysms was $71.6 \%$ (101/141). The rate of angiographic occlusion of ruptured aneurysms treated with flow diversion at last follow-up was $90.2 \%$ (101/112).

\section{Meta-analysis}

\section{Individual Participant Data Meta-Analysis}

The odds ratio for overall complication (primary outcome) rate for early vs. delayed flow diversion was 0.95 (95\% CI 0.36-2.49, Cochran Q statistic $\mathrm{p}=0.42$ ). However, the odds ratio for secondary outcomes of hemorrhagic complication for early vs. delayed flow diversion was 1.44 (95\% CI 0.45-4.52, Cochran Q statistic $\mathrm{p}=0.87$ ) and of stroke/death for early vs. delayed flow diversion was 1.67 (95\% CI 0.5-4.9, Cochran Q statistic $\mathrm{p}=0.69)$. In summary, the results indicate no difference in overall complication rate between early vs. delayed flow diversion, but a higher (although not statistically significant) risk for hemorrhagic complications and for stroke/death in the early group (Figure 2). The L'Abbé plots for the primary and secondary outcomes show that 3 studies had higher risk for overall complication with early treatment, 4 studies had higher risk for hemorrhage with early treatment, and 4 studies had higher risk for stroke/death with early treatment (Figure 3).

We performed a subgroup analysis of odds ratios for overall complications in the early vs. delayed treatment groups based on patient age, aneurysm location and aneurysm morphology (Figure 4). The odds ratio of early ys. delayed flow diversion was 1.39 (95\% CI 0.48-4.00) for patients $\leq 60$ years and 0.55 (95\% CI 0.09-3.48) for patients $>60$ years, but the difference in odds ratios was not statistically significant (Cochran $\mathrm{Q}$ statistic $\mathrm{p}=0.44)$. The odds ratio of early vs. delayed flow diversion was 0.82 (95\% CI 0.29-2.30) for blister/dissecting/fusiform aneurysms and 2.23 (95\% CI 0.17-29.4) for saccular/giant aneurysms, but the difference in odds ratios was not statistically significant (Cochran Q statistic $\mathrm{p}=0.43$ ). Finally, the odds ratio of early vs. delayed flow diversion was 1.62 (95\% CI 0.5-4.9) for patients with anterior circulation aneurysms and 0.28 (95\% CI $0.05-1.65)$ for patients with posterior circulation aneurysms, but the difference in odds ratios was not statistically significant (Cochran $Q$ statistic $p=0.14$ ). The 
meta-regression with bubble plots further demonstrate that the differences in summary estimates between the subgroups were not statistically significant (Figure 5).

2. Proportion meta-analysis:

11 studies (with 92 patients) reported outcomes on early flow-diverter treatment, whereas 10 studies (with 53 patients) reported outcomes on delayed flow-diverter treatment. The pooled percentage of overall complication rate was 33\% (95\% CI $0.22-0.44$ ) in the early treatment group and $22 \%$ (95\% CI 0.10-0.37) in the delayed treatment group (Figure 6). The pooled percentage of hemorrhage was $14 \%$ (95 CI-0.06, 0.23) in the early treatment group and 5\% (95\% CI-0.000.15 ) in the delayed treatment group. Finally, the pooled percentage of stroke/death was $29 \%$ (95\% CI 0.18-0.40) in the early treatment group and $11 \%$ (95\% CI 0.02-0.24) in the delayed treatment group. Meta-regression between the two groups did not identify any significant difference of proportions for overall complication, hemorrhage or stroke/death (Figure 7).

\section{Quality of studies and Bias assessment}

Most studies scored "fair" in the National Heart, Lung and Blood Institute (NHLBI) Quality Assessment Tool for observational studies. Funnel tests for outcome parameters did not show any significant publication bias. 


\section{DISCUSSION}

\section{Impact of timing of flow diversion on overall complication rate}

This meta-analysis of 13 studies analyzing the use of primary flow diversion (i.e. without prior coiling or adjunctive aneurysm treatment) for ruptured aneurysms did not find a statistically significant difference in the overall complication rate (primary outcome) between the early or delayed treatment groups $(\mathrm{OR}=0.95,95 \%$ CI 0.36-2.49, Cochran $\mathrm{Q}$ statistic $\mathrm{p}=0.42)$. However, with respect to the secondary outcomes of hemorrhage and stroke/death, the results demonstrated a higher (although not statistically significant) risk of hemorrhagic complications ( $\mathrm{OR}=1.44$, 95\% CI 0.45-4.52, Cochran Q statistic p=0.87) and of stroke/death (OR=1.67, 95\% CI 0.5-4.9, Cochran $\mathrm{Q}$ statistic $\mathrm{p}=0.69$ ) in the early group. It is important to note that the objective of this study was not to evaluate the overall safety of flow diversion for ruptured aneurysms but to evaluate whether timing of flow diversion for ruptured aneurysms has an impact on the overall complication rate. Therefore, the overall results of the meta-analysis suggest that the timing of flow diversion does not impact the overall complication rate and that the risk of hemorrhagic complications and of stroke/death is slightly higher with early flow diversion.

Flow diversion for ruptured aneurysms carries inherent risks: (1) flow diversion leads to delayed aneurysm occlusion, and therefore there is a risk for aneurysm rerupture; and (2) dual antiplatelet therapy may exacerbate bleeding from SAH and from necessary procedures (central venous catheters, ventriculostomies, ventriculoperitoneal shunting, etc.). Ideally, ruptured aneurysms should be secured as soon as possible following SAH without the use of antiplatelet therapy. However, certain aneurysm morphologies (such as giant, blister, fusiform or dissecting) are considered "challenging" because they are difficult to treat with conventional endovascular or neurosurgical modalities. Conventional endovascular treatment options for these "challenging" aneurysms include reconstructive (e.g. balloon-stent assisted coiling) and deconstructive (e.g. parent vessel sacrifice) treatments, ${ }^{32}$ while conventional neurosurgical treatments include aneurysm wrapping or trapping with bypass. Often, in treating "challenging" ruptured aneurysms, these conventional endovascular or neurosurgical treatments are not possible or are associated with high rates of perioperative morbidity and mortality. ${ }^{33}$ Flow diversion has therefore emerged as a viable treatment option for such "challenging" aneurysms. Accordingly, 
the issue of timing of flow diversion following SAH is most applicable in the treatment of "challenging" ruptured aneurysms. The following section discusses the relationship between morphology of "challenging" ruptured aneurysm and timing of flow diversion on overall complication rate.

\section{Relationship between ruptured aneurysm morphology and timing of flow diversion on overall complication rate}

The subgroup analysis of "challenging" ruptured aneurysm morphology favored $(\mathrm{OR}=0.82,95 \%$ $\mathrm{CI}=0.29-2.30$ ) early treatment for ruptured blister, fusiform or dissecting aneurysms, but did not favor ( $\mathrm{OR}=2.23,95 \% \mathrm{CI}=0.17-29.4)$ early treatment of giant saccular aneurysms, although the difference in odds ratios was not statistically significant (Cochran $Q$ statistic $p=0.43$ ). In addition, of the 5 aneurysms that reruptured in the entire systematic review, the morphology was saccular in $40 \%(2 / 5)$ and the rerupture rate was $42.9 \%$ (3/7) for all aneurysms larger than $2 \mathrm{~cm}$. More importantly, all aneurysm reruptures occurred during the early treatment phase and carried a mortality of $100 \%(5 / 5)$. These data from both the subgroup meta-analysis and the systematic review suggest significant risks for flow diversion in the early treatment group for saccular aneurysms that are larger than $2 \mathrm{~cm}$.

Given the high risk of rerupture and subsequent mortality from primary flow diversion for large, saccular ruptured aneurysms, a new endovascular treatment paradigm of acute coiling followed by staged flow diversion appears to be a safer endovascular option for these ruptured aneurysms.

${ }^{34}$ Brinjikji et al. reported results for acute coiling followed by delayed flow diversion (median time of 16 weeks between the coiling and flow diversion) in 27 patients who had SAH from large/giant ruptured aneurysms. One patient developed rerupture after coiling but before flow diversion. At last follow up, 18 patients had complete or near complete aneurysm occlusion, and 25 patients had good performance status (mRS score $0-2) .{ }^{34}$ The excellent results reported in this study are likely due to the reduced risk of hemorrhagic complications-especially aneurysm rerupture-from dual antiplatelet therapy for delayed flow diversion for large/giant saccular ruptured aneurysms. 
On the other hand, as demonstrated by this meta-analysis, the safety profile of $\boldsymbol{e}$ arly flow diversion for ruptured blister, dissecting, or fusiform aneurysms is more favorable than that for ruptured giant saccular aneurysms, although the difference was not statistically significant. Perhaps it is fortuitous that blister, dissecting or fusiform aneurysms are more favorable to treat in the early phase with flow diversion because, unlike giant saccular aneurysms, these aneurysms are not amenable to primary coil embolization. From an open neurosurgical approach, blister, fusiform and dissecting aneurysms require a combination of aneurysm wrapping, aneurysm trapping and bypass or parent vessel sacrifice, all of which are associated with high procedural morbidity. There is evidence that endovascular approaches are superior to neurosurgical approaches in the treatment of blister, fusiform and dissecting aneurysms. A meta-analysis comparing a variety of neurosurgical and endovascular treatments for ruptured blister aneurysms concluded that endovascular treatments were associated with lower morbidity and mortality as compared to neurosurgical approaches. ${ }^{32}$ A series of 5 patients with ruptured blister aneurysms treated with flow diversion demonstrated favorable performance status (mRS 0-2) in all 5 patients with aneurysm occlusion rate of $100 \% .{ }^{24}$ Lin et al. published a series of 26 ruptured aneurysms treated with flow diversion, 8 of which had blister morphology; all 8 patients had complete aneurysm occlusion at last followup and $7 / 8$ patients had a good outcome. ${ }^{25}$ In both of the above case series, the timing of intervention (early vs. delayed) did not influence clinical outcomes or angiographic occlusion rates.

\section{Limitations}

The chief limitation of this meta-analysis is the small number of included studies $(n=13)$ with small sample size of comparison groups, which reflects the lack of data published on flow diversion for ruptured aneurysms. The Individual Participant Data (IPD) meta-analysis included only 7 studies. To overcome the limitations of the IPD meta-analysis, a Proportion meta-analysis including all 13 studies was performed. Both IPD and proportion meta-analyses incorporated case series performed at different institutions. Therefore, the conclusions of the meta-analyses are limited by differences in institutional protocols for flow diversion for ruptured aneurysms (e.g. choice of antiplatelet regimen and timing of flow diversion following SAH). An important limitation of the current meta-analysis is the nature of the studies. All the included studies are case series and do not include any experimental arm pertinent to our research question. Similarly, 
the individual patient data collected for our analysis are derived from the published series in which the patients were not treated with a predefined protocol and therefore include a significant diversity. Therefore, the results of this meta-analysis may not serve as a strong evidence regarding formulating or modifying treatment guideline, but can possibly serve as a baseline research for future large-scale randomized studies. 


\section{CONCLUSIONS}

Flow diversion for ruptured intracranial aneurysms is safe and effective in achieving aneurysm occlusion and favorable patient outcomes. This meta-analysis did not show a difference in overall complication rate (primary outcome) between early vs. delayed flow diversion for ruptured aneurysms. However, clinical judgment is paramount in selecting patients with ruptured aneurysms for treatment with flow diversion. Early flow diversion for ruptured blister/fusiform/dissecting aneurysms carries a lower risk of aneurysm rerupture and overall complications as compared to that for ruptured saccular/giant aneurysms. Randomized controlled trials comparing flow diversion to standard treatment for ruptured aneurysms will further elucidate the safety and efficacy of flow diversion for ruptured aneurysms. 


\section{REFERENCES}

1. Molyneux A, Kerr R, Stratton I, et al. International Subarachnoid Aneurysm Trial (ISAT) of neurosurgical clipping versus endovascular coiling in 2143 patients with ruptured intracranial aneurysms: a randomised trial. Lancet Lond Engl. 2002;360(9342):1267-1274.

2. Molyneux AJ, Birks J, Clarke A, Sneade M, Kerr RSC. The durability of endovascular coiling versus neurosurgical clipping of ruptured cerebral aneurysms: 18 year follow-up of the UK cohort of the International Subarachnoid Aneurysm Trial (ISAT). Lancet Lond Engl. 2015;385(9969):691-697. doi:10.1016/S0140-6736(14)60975-2

3. Brisman JL, Song JK, Newell DW. Cerebral aneurysms. N Engl J Med. 2006;355(9):928939. doi:10.1056/NEJMra052760

4. Spetzler RF, McDougall CG, Zabramski JM, et al. The Barrow Ruptured Aneurysm Trial: 6-year results. J Neurosurg. 2015;123(3):609-617. doi:10.3171/2014.9.JNS141749

5. Kallmes DF, Hanel R, Lopes D, et al. International retrospective study of the pipeline embolization device: a multicenter aneurysm treatment study. AJNR Am J Neuroradiol. 2015;36:108-115. doi:10.3174/ajnr.A4111

6. Kallmes DF, Brinjikji W, Cekirge S, et al. Safety and efficacy of the Pipeline embolization device for treatment of intracranial aneurysms: a pooled analysis of 3 large studies. $J$ Neurosurg. 2017;127:775-780. doi:10.3171/2016.8.jns16467

7. Aguilar-Salinas P, Brasiliense LB, Gonsales D, et al. Evaluation of Pipeline Flex delivery system for the treatment of unruptured aneurysms. Expert Rev Med Devices. 2016;13:885897. doi:10.1080/17434440.2016.1231573

8. Eller JL, Dumont TM, Sorkin GC, et al. The Pipeline embolization device for treatment of intracranial aneurysms. Expert Rev Med Devices. 2014;11:137-150. doi:10.1586/17434440.2014.877188

9. Walcott BP, Stapleton CJ, Choudhri O, Patel AB. Flow Diversion for the Treatment of Intracranial Aneurysms. JAMA Neurol. 2016;73:1002-1008.

doi:10.1001/jamaneurol.2016.0609

10. Walcott BP, Koch MJ, Stapleton CJ, Patel AB. Blood Flow Diversion as a Primary Treatment Method for Ruptured Brain Aneurysms-Concerns, Controversy, and Future Directions. Neurocrit Care. 2017;26:465-473. doi:10.1007/s12028-016-0318-y

11. Heller RS, Dandamudi V, Lanfranchi M, Malek AM. Effect of antiplatelet therapy on thromboembolism after flow diversion with the pipeline embolization device. J Neurosurg. 2013;119:1603-1610. doi:10.3171/2013.7.jns122178 
12. Kamran M, Yarnold J, Grunwald IQ, Byrne JV. Assessment of angiographic outcomes after flow diversion treatment of intracranial aneurysms: a new grading schema. Neuroradiology. 2011;53:501-508. doi:10.1007/s00234-010-0767-5

13. McAuliffe W, Wenderoth JD. Immediate and midterm results following treatment of recently ruptured intracranial aneurysms with the Pipeline embolization device. AJNR Am J Neuroradiol. 2012;33:487-493. doi:10.3174/ajnr.A2797

14. Chalouhi N, Zanaty M, Whiting A, et al. Treatment of ruptured intracranial aneurysms with the pipeline embolization device. Neurosurgery. 2015;76:165-172; discussion 172. doi:10.1227/neu.0000000000000586

15. Aydin K, Barburoglu M, Sencer S, Berdikhojayev M, Coskun B, Akpek S. Flow Diversion with Low-Profile Braided Stents for the Treatment of Very Small or Uncoilable Intracranial Aneurysms at or Distal to the Circle of Willis. AJNR Am J Neuroradiol. 2017;38:21312137. doi:10.3174/ajnr.A5362

16. Cerejo R, Bain M, Moore N, et al. Flow diverter treatment of intracranial vertebral artery dissecting pseudoaneurysms. J Neurointerv Surg. 2017;9:1064-1068. doi:10.1136/neurintsurg-2017-013020

17. Cerejo R, Bain M, John S, et al. Flow diverter treatment of cerebral blister aneurysms. Neuroradiology. 2017;59:1285-1290. doi:10.1007/s00234-017-1936-6

18. Duman E, Coven I, Yildirim E, Yilmaz C, Pinar HU. Endovascular Treatment of Wide Necked Ruptured Saccular Aneurysms with Flow-Diverter Stent. Turk Neurosurg. 2017;27:362-367. doi:10.5137/1019-5149.jtn.16324-15.1

19. Guerrero WR, Ortega-Gutierrez S, Hayakawa M, et al. Endovascular Treatment of Ruptured Vertebrobasilar Dissecting Aneurysms Using Flow Diversion Embolization Devices: Single-Institution Experience. World Neurosurg. 2018;109:e164-e169. doi:10.1016/j.wneu.2017.09.125

20. Lozupone E, Piano M, Valvassori L, et al. Flow diverter devices in ruptured intracranial aneurysms: a single-center experience. J Neurosurg. April 2017:1-7. doi:10.3171/2016.11.jns161937

21. Maus V, Mpotsaris A, Dorn F, et al. The Use of Flow Diverter in Ruptured, Dissecting Intracranial Aneurysms of the Posterior Circulation. World Neurosurg. 2018;111:e424e433. doi:10.1016/j.wneu.2017.12.095

22. Natarajan SK, Shallwani H, Fennell VS, et al. Flow Diversion after Aneurysmal Subarachnoid Hemorrhage. Neurosurg Clin N Am. 2017;28:375-388. doi:10.1016/j.nec.2017.02.011

23. Ryan RW, Khan AS, Barco R, Choulakian A. Pipeline flow diversion of ruptured blister aneurysms of the supraclinoid carotid artery using a single-device strategy. Neurosurg Focus. 2017;42:E11. doi:10.3171/2017.3.focus 1757 
24. Chalouhi N, Zanaty M, Tjoumakaris S, et al. Treatment of blister-like aneurysms with the pipeline embolization device. Neurosurgery. 2014;74(5):527-532; discussion 532. doi:10.1227/NEU.0000000000000309

25. Lin N, Brouillard AM, Keigher KM, et al. Utilization of Pipeline embolization device for treatment of ruptured intracranial aneurysms: US multicenter experience. J Neurointerv Surg. 2015;7:808-815. doi:10.1136/neurintsurg-2014-011320

26. Aydin K, Arat A, Sencer S, et al. Treatment of ruptured blood blister-like aneurysms with flow diverter SILK stents. J Neurointerv Surg. 2015;7:202-209. doi:10.1136/neurintsurg2013-011090

27. Shamseer L, Moher D, Clarke M, et al. Preferred reporting items for systematic review and meta-analysis protocols (PRISMA-P) 2015: elaboration and explanation. BMJ. 2015;350:g7647.

28. Study Quality Assessment Tools | National Heart, Lung, and Blood Institute (NHLBI). https://www.nhlbi.nih.gov/health-topics/study-quality-assessment-tools. Accessed July 16, 2018.

29. Debray TPA, Moons KGM, van Valkenhoef G, et al. Get real in individual participant data (IPD) meta-analysis: a review of the methodology. Res Synth Methods. 2015;6(4):293-309. doi:10.1002/jrsm.1160

30. Nyaga VN, Arbyn M, Aerts M. Metaprop: a Stata command to perform meta-analysis of binomial data. Arch Public Health. 2014;72:39. doi:10.1186/2049-3258-72-39

31. Chan RS, Mak CH, Wong AK, Chan KY, Leung KM. Use of the pipeline embolization device to treat recently ruptured dissecting cerebral aneurysms. Interv Neuroradiol. 2014;20:436-441. doi:10.15274/nrj-2014-10042 10.15274/inr-2014-10042

32. Rouchaud A, Brinjikji W, Cloft HJ, Kallmes DF. Endovascular Treatment of Ruptured Blister-Like Aneurysms: A Systematic Review and Meta-Analysis with Focus on Deconstructive versus Reconstructive and Flow-Diverter Treatments. AJNR Am J Neuroradiol. 2015;36:2331-2339. doi:10.3174/ajnr.A4438

33. Kalani MYS, Zabramski JM, Kim LJ, et al. Long-term follow-up of blister aneurysms of the internal carotid artery. Neurosurgery. 2013;73(6):1026-1033; discussion 1033. doi:10.1227/NEU.0000000000000147

34. Brinjikji W, Piano M, Fang S, et al. Treatment of ruptured complex and large/giant ruptured cerebral aneurysms by acute coiling followed by staged flow diversion. J Neurosurg. 2016;125:120-127. doi:10.3171/2015.6.jns151038 


\section{FIGURE LEGENDS}

Figure 1: Selection process for included studies using Preferred Reporting Items for Systematic Reviews and Meta-analysis (PRISMA) protocol

Figure 2: Forest plots from Individual Participant Data (IPD) meta-analysis showing the pooled odds ratios with $95 \%$ confidence intervals for overall complication (A), hemorrhage (B) and Stroke/Death (C). MH Q statistics: Cochran Q statistics using Mantel-Haenszel method.

Figure 3: L'Abbé plots showing the risk of overall complication (A), hemorrhage (B) and stroke/death (C) as seen in individual studies. The size of the circles represents the sample size. The solid line represents the estimated overall odds ratio. The dashed line represents the line of no-effect.

Figure 4: Forest plots showing subgroup analysis for moderators including age, type of aneurysm and location of the aneurysm. MH Q statistics: Cochran Q statistics using Mantel-Haenszel method

Figure 5: Meta-regression analysis with bubble plots showing difference in summary estimates by different moderators, age (A), type of aneurysm (B), Location of the aneurysm (C). The solid line represents regression line.

Figure 6: Forest plots from proportion meta-analysis showing pooled proportions of overall complication, hemorrhage and stroke/death with early and delayed treatment.

Figure 7: Meta-regression analysis with bubble plots showing difference in summary estimates for overall complication (A), hemorrhage (B) and stroke/death (C) between early and delayed treatment. The solid line represents regression line.

Figure 8: Funnel plots for publication bias in reporting overall complication, hemorrhage and stroke/death.

\section{TABLE LEGENDS}

Table 1: Summary of characteristics for each of the included studies 


\begin{tabular}{|c|c|c|c|c|c|c|c|c|c|c|c|c|}
\hline $\begin{array}{l}\text { Study, } \\
\text { year }\end{array}$ & $\begin{array}{c}\text { No of } \\
\text { Patients }\end{array}$ & $\begin{array}{l}\text { Age } \\
\text { Mean }\end{array}$ & $\begin{array}{c}\text { Timing of } \\
\text { Intervention } \\
\text { (Early } \\
\text { /Delayed) }\end{array}$ & $\begin{array}{c}\text { Aneurysm } \\
\text { Size in } \\
\text { mm } \\
\text { (Mean) }\end{array}$ & $\begin{array}{c}\text { Pre- } \\
\text { procedure } \\
\text { Antiplatelet } \\
\text { Regimen }\end{array}$ & $\begin{array}{l}\text { Type of } \\
\text { Flow } \\
\text { Diverter }\end{array}$ & $\begin{array}{l}\text { Adjunctive } \\
\text { Treatment }\end{array}$ & Location & $\begin{array}{c}\text { Aneurysm } \\
\text { Shape }\end{array}$ & $\begin{array}{c}\text { Aneurysm } \\
\text { occlusion } \\
\text { Rates }^{2}\end{array}$ & $\begin{array}{c}\text { Duration } \\
\text { of } \\
\text { Follow- } \\
\text { up }\end{array}$ & $\begin{array}{c}\text { Favorable } \\
\text { outcome at } \\
\text { last follow- } \\
\text { Up }^{3}\end{array}$ \\
\hline $\begin{array}{c}\text { McAullife et } \\
\text { al, } 2012\end{array}$ & $8(3)$ & 51.4 & $3 \backslash 5$ & 14.3 & $\begin{array}{c}600 \mathrm{mg} \\
\text { clopidogrel } \\
+300 \mathrm{mg} \\
\text { aspirin }\end{array}$ & All PED & 3 (coil) & $\begin{array}{c}4 \\
\text { Anterior } \\
4 \\
\text { Posterior }\end{array}$ & $\begin{array}{l}3 \text { saccular } \\
3 \text { fusiform } \\
2 \text { blister }\end{array}$ & $\begin{array}{c}6 / 6 \\
(100 \%)\end{array}$ & 6 months & $75 \%$ \\
\hline $\begin{array}{l}\text { Chalouhi et } \\
\text { al, } 2014\end{array}$ & 5 & 57.8 & $2 \backslash 3$ & 2.2 & $\begin{array}{c}600 \mathrm{mg} \\
\text { clopidogrel } \\
+650 \mathrm{mg} \\
\text { aspirin } \\
\end{array}$ & All PED & None & $\begin{array}{c}4 \\
\text { Anterior } \\
1 \\
\text { Posterior } \\
\end{array}$ & All blister & $\begin{array}{l}4 \text { of } 5 \\
(80 \%)\end{array}$ & 6 months & $100 \%$ \\
\hline $\begin{array}{c}\text { Chan et al, } \\
2014\end{array}$ & 8 & 51.8 & $4 \backslash 4$ & 7.3 & $\begin{array}{c}\text { 300mg } \\
\text { clopidogrel } \\
+320 \mathrm{mg} \\
\text { aspirin } \\
\end{array}$ & All PED & None & $\begin{array}{c}\text { All } \\
\text { Posterior }\end{array}$ & $\begin{array}{c}\text { All } \\
\text { Dissecting }\end{array}$ & $\begin{array}{l}8 \text { of } 8 \\
(100 \%)\end{array}$ & 6 months & $37.5 \%$ \\
\hline $\begin{array}{l}\text { Aydin et al, } \\
2015\end{array}$ & 11 & 49.5 & All delayed & 3.2 & $\begin{array}{c}600 \mathrm{mg} \\
\text { clopidogrel } \\
+300 \mathrm{mg} \\
\begin{array}{c}\text { aspirin } \\
\end{array}\end{array}$ & All SILK & 1 (stent) & $\begin{array}{c}9 \\
\text { Anterior } \\
2 \\
\text { Posterior } \\
\end{array}$ & All blister & $\begin{array}{l}10 \text { of } 10 \\
(100 \%)\end{array}$ & 6 months & $90.9 \%$ \\
\hline $\begin{array}{l}\text { Chalouhi et } \\
\text { al, } 2015\end{array}$ & $16(4)$ & 49 & $12 \backslash 4$ & 5.4 & $\begin{array}{c}600 \mathrm{mg} \\
\text { clopidogrel } \\
+650 \mathrm{mg} \\
\text { aspirin }\end{array}$ & All PED & None & $\begin{array}{c}11 \\
\text { Anterior } \\
5 \\
\text { Posterior }\end{array}$ & $\begin{array}{c}12 \\
\text { saccular } \\
4 \\
\text { dissecting }\end{array}$ & $\begin{array}{c}10 \text { of } 15 \\
(67 \%)\end{array}$ & $\begin{array}{c}2-12 \\
\text { months }\end{array}$ & $93.75 \%$ \\
\hline $\begin{array}{c}\text { Lin et al, } \\
2015\end{array}$ & $18(8)$ & NR & All early & 7.2 & NR & All PED & 5 (coil) & $\begin{array}{c}15 \\
\text { Anterior } \\
3 \\
\text { Posterior }\end{array}$ & $\begin{array}{l}2 \text { saccular } \\
8 \text { fusiform } \\
8 \text { blister }\end{array}$ & $\begin{array}{c}15 \text { of } 18 \\
(83 \%)\end{array}$ & $\begin{array}{c}2-21 \\
\text { months }\end{array}$ & $72.2 \%$ \\
\hline
\end{tabular}




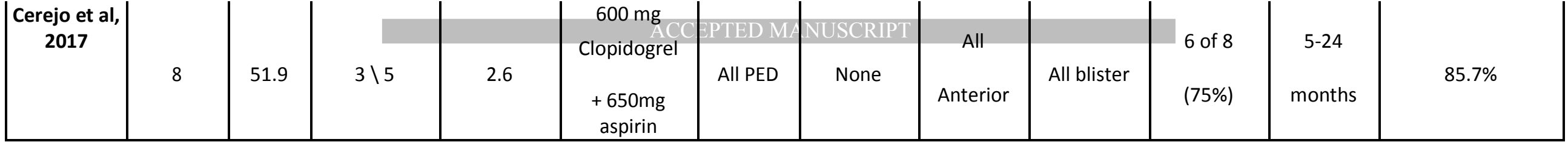

\begin{tabular}{|c|c|c|c|c|c|c|c|c|c|c|c|c|}
\hline $\begin{array}{c}\text { Duman et al, } \\
2017\end{array}$ & 5 & 61.4 & All delayed & 10.3 & $\begin{array}{c}600 \mathrm{mg} \\
\text { clopidogrel }\end{array}$ & All SILK & 3 (coil) & $\begin{array}{c}\text { All } \\
\text { Anterior }\end{array}$ & $\begin{array}{c}\text { All } \\
\text { saccular }\end{array}$ & $\begin{array}{l}4 \text { of } 4 \\
(100 \%)\end{array}$ & $\begin{array}{c}\text { 4-17 } \\
\text { months }\end{array}$ & $80 \%$ \\
\hline $\begin{array}{c}\text { Guerrero et } \\
\text { al, } 2017\end{array}$ & 9 & NR & All early & 5.1 & $\begin{array}{c}0.1 \mathrm{mcg} / \mathrm{kg} / \\
\mathrm{min} \text { infusion } \\
\text { of Tirofiban } \\
\text { postprocedu } \\
\text { re for } 2-6 \mathrm{hrs} \\
+600 \mathrm{mg} \\
\text { clopidogrel } \\
+325 \mathrm{mg} \\
\text { aspirin }\end{array}$ & All PED & None & All & All & $\begin{array}{c}5 \text { of } 8 \\
(62.5 \%)\end{array}$ & $\begin{array}{l}\text { 1-12 } \\
\text { months }\end{array}$ & $77.8 \%$ \\
\hline $\begin{array}{c}\text { Lozupone et } \\
\text { al, } 2017\end{array}$ & 17 & 46.6 & $11 \backslash 6$ & NR & $\begin{array}{c}\text { abciximab } \\
\text { bolus } \\
\text { followed by } \\
\text { infusion } \\
\text { following } \\
\text { flow diverter } \\
\text { deployment }\end{array}$ & $\begin{array}{l}\text { PED (14 } \\
\text { pts) } \\
\text { SILK (2 } \\
\text { pts) } \\
\text { Surpass } \\
\text { (1 pt) }\end{array}$ & 2 (coil) & $\begin{array}{c}10 \\
\text { Anterior } \\
7 \\
7 \\
\text { Posterior }\end{array}$ & $\begin{array}{c}8 \text { blister } \\
9 \\
9 \\
\text { dissecting }\end{array}$ & $\begin{array}{c}12 \text { of } 17 \\
(71 \%)\end{array}$ & $\begin{array}{c}\text { 6-12 } \\
\text { months }\end{array}$ & $70.6 \%$ \\
\hline $\begin{array}{c}\text { Maus et al, } \\
2017,\end{array}$ & $14(1)$ & 56.1 & All early & 6.4 & $\begin{array}{l}\text { Tirofiban } \\
\text { bolus } \\
\text { followed } \\
\text { by infusion }\end{array}$ & All PED & $\begin{array}{l}2 \text { (coil) } \\
1 \text { (stent) }\end{array}$ & $\begin{array}{c}\text { All } \\
\text { Posterior }\end{array}$ & $\begin{array}{c}\text { All } \\
\text { dissecting }\end{array}$ & $\begin{array}{l}6 \text { of } 7 \\
(86 \%)\end{array}$ & $\begin{array}{c}\text { 1-12 } \\
\text { months }\end{array}$ & $21.4 \%$ \\
\hline $\begin{array}{l}\text { Natarajan } \\
\text { et al, } 2017\end{array}$ & $10(1)$ & 52.4 & $8 \backslash 2$ & NR & $\begin{array}{c}600 \mathrm{mg} \\
\text { clopidorel } \\
+650 \mathrm{mg} \\
\text { aspirin } \\
\text { or aspirin + } \\
\text { prasugrel } \\
\text { or aspirin + } \\
\text { ticagrelor }\end{array}$ & All PED & 1 (coil) & $\begin{array}{c}7 \\
\text { Anterior } \\
3 \\
\text { Posterior }\end{array}$ & $\begin{array}{c}3 \text { saccular } \\
4 \text { blister } \\
2 \\
\text { dissecting } \\
1 \text { fusiform }\end{array}$ & $\begin{array}{l}8 \text { of } 8 \\
(100 \%)\end{array}$ & $\begin{array}{c}1-44 \\
\text { months }\end{array}$ & $80 \%$ \\
\hline $\begin{array}{l}\text { Ryan et al, } \\
2017,\end{array}$ & 13 & 54.8 & $5 \backslash 8$ & 1.9 & $\begin{array}{c}\text { 600mg } \\
\text { clopidogrel }\end{array}$ & All PED & None & All & All blister & 6 of 11 & $1.5-12$ & $76.9 \%$ \\
\hline
\end{tabular}


Table 1: Summary of characteristics for each of the thirteen included studies.

\section{NR-Not reported}

${ }^{1}$ Numbers in parentheses denote excluded patients due to previous treatment or no flow diverter used

${ }^{2}$ Aneurysm occlusion rates calculated from available data

${ }^{3}$ Favorable outcome $=$ mRS scale 0-2 or Glasgow Outcome Score 4-5 
Table 2: Demographic and clinical characteristics between two treatment arms

\begin{tabular}{|c|c|c|c|c|}
\hline \multicolumn{2}{|c|}{ Characteristic } & $\begin{array}{c}\text { Early Treatment } \\
\text { Group } \\
(n=89)\end{array}$ & $\begin{array}{c}\text { Delayed treatment } \\
\text { Group } \\
(n=53)\end{array}$ & $p$-value \\
\hline \multicolumn{2}{|l|}{ Age (Mean) } & 55.2 & 51.8 & 0.18 \\
\hline \multicolumn{2}{|l|}{ Size (in $\mathrm{mm}$ ) } & 6.8 & 4.7 & 0.04 \\
\hline \multirow{2}{*}{ Type of aneurysm } & $\begin{array}{l}\text { Blister / Dissecting / } \\
\text { Fusiform aneurysm }\end{array}$ & 76 & 41 & \multirow{2}{*}{0.25} \\
\hline & Saccular aneurysm & 13 & 12 & \\
\hline \multirow{2}{*}{$\begin{array}{l}\text { Location of the } \\
\text { aneurysm }\end{array}$} & Anterior circulation & 46 & 41 & \multirow[b]{2}{*}{0.002} \\
\hline & $\begin{array}{l}\text { Posterior } \\
\text { circulation }\end{array}$ & 43 & 12 & \\
\hline \multirow{2}{*}{ Presentation grade } & $\begin{array}{l}\text { Good grade (WFNS } \\
1-2 \text { ) }\end{array}$ & 40 & 40 & \multirow{2}{*}{0.004} \\
\hline & Poor grade $(>3)$ & 49 & 13 & \\
\hline
\end{tabular}




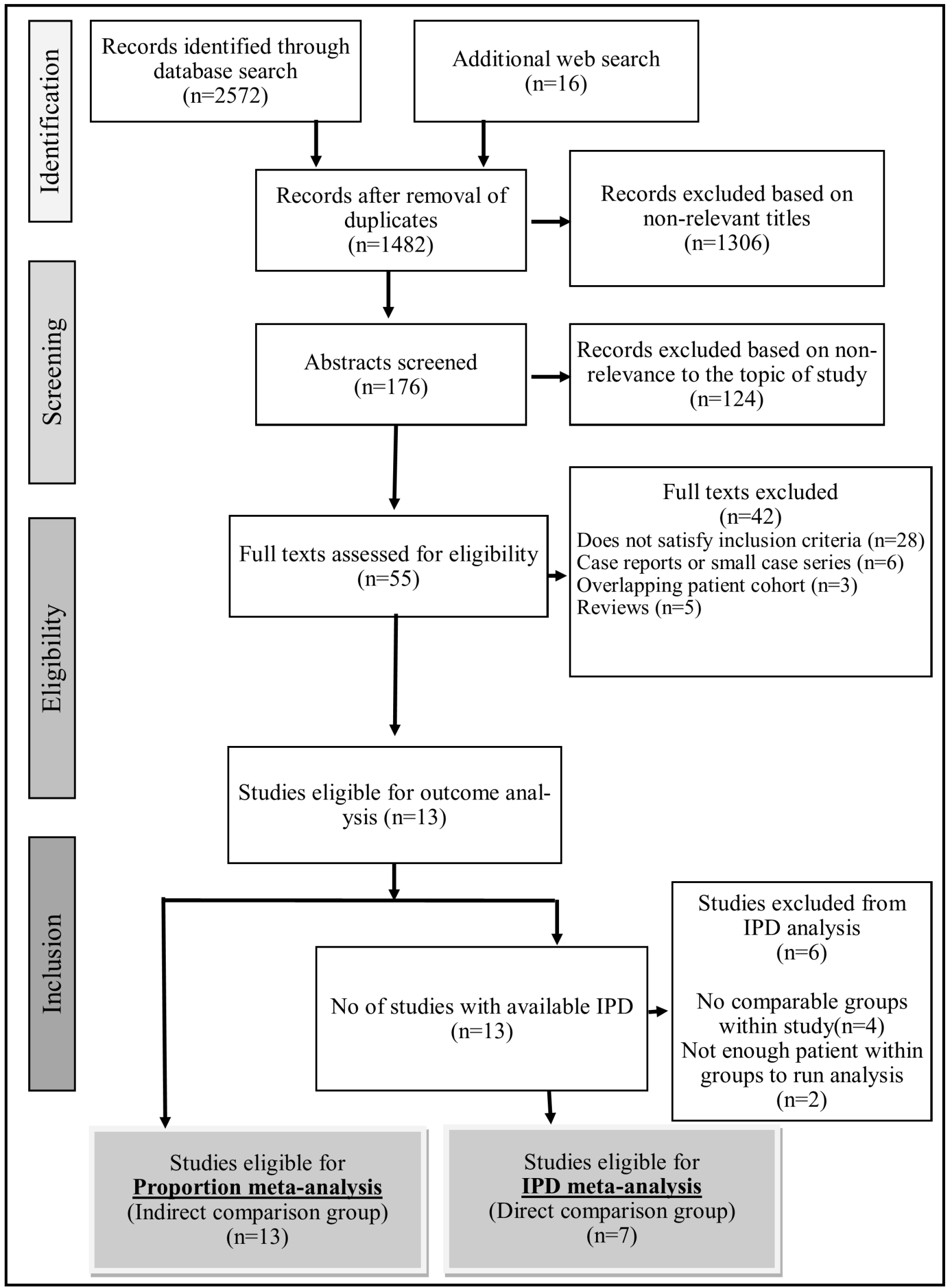




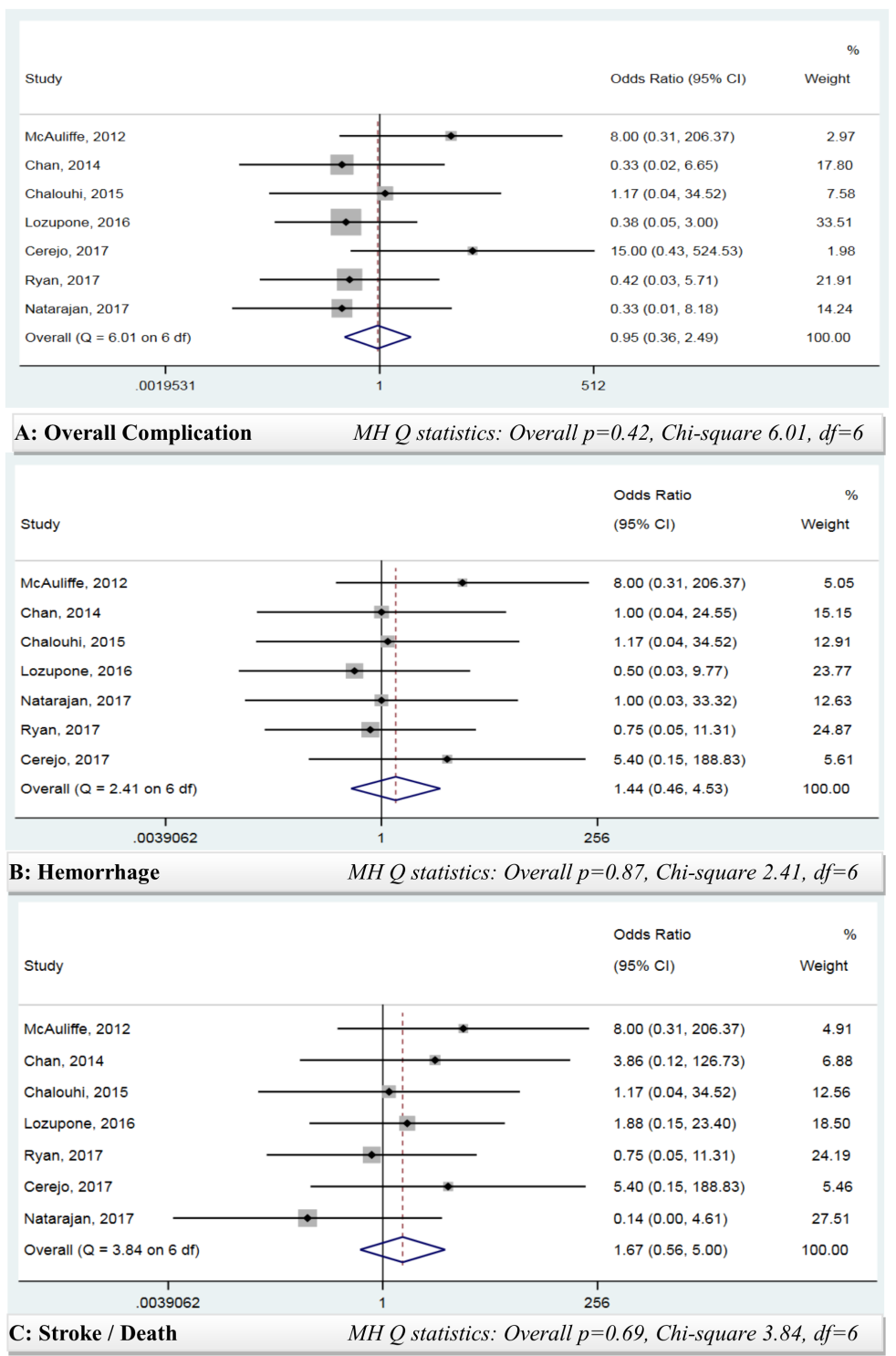



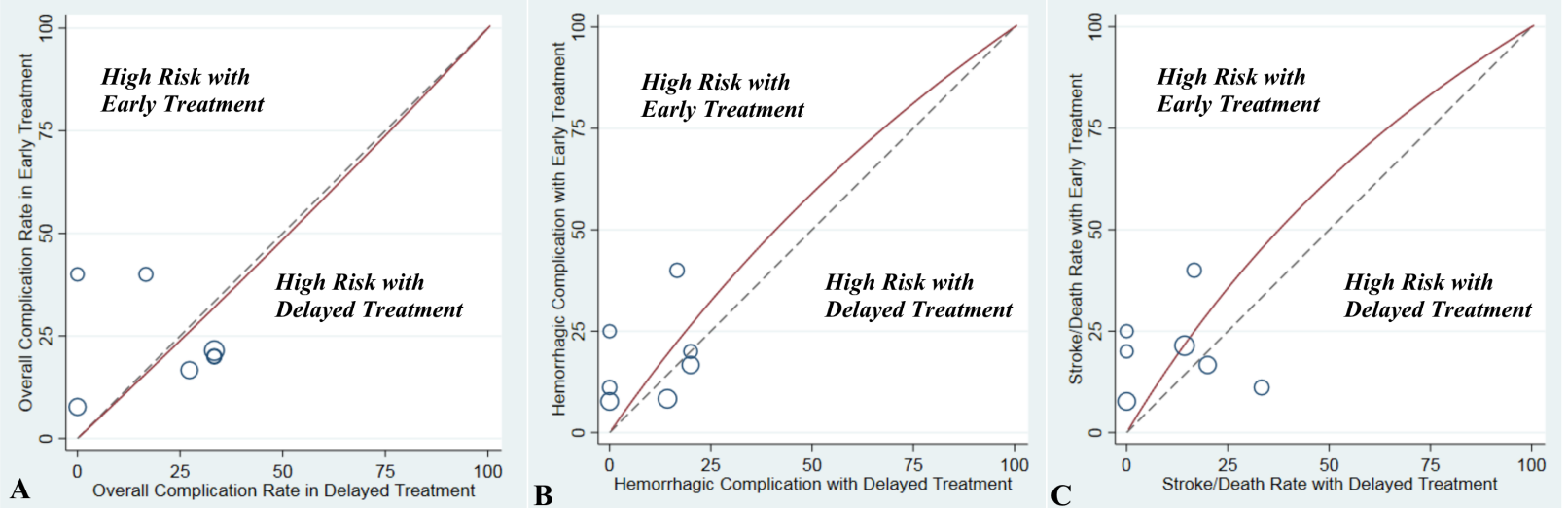

C 
Age

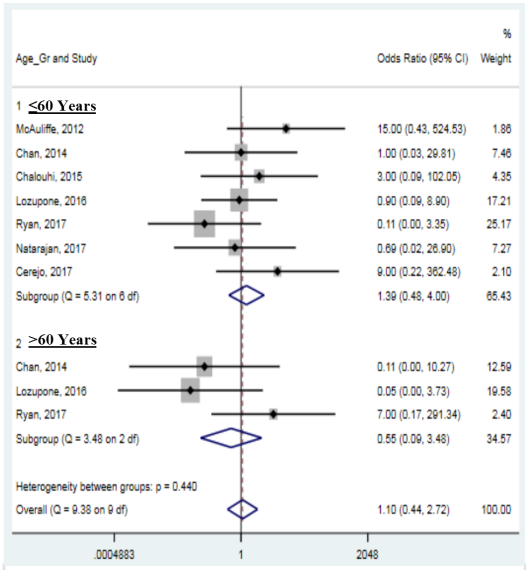

MH $Q$ statistics

Overall $p=0.40$, Chi-square 9.38, $d f=9$

Between group $p=0.44$, Chi-square 0.60, $d f=1$

\section{Type of Aneurysm}

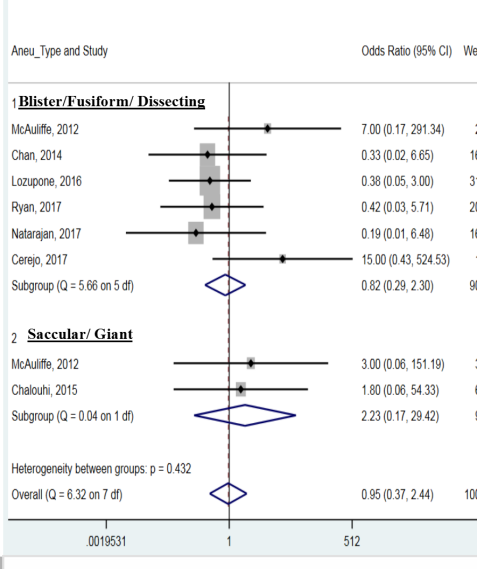

MHQ statistics

Overall $p=0.50$, Chi-square 6.32, $d f=7$ Between group $p=0.43$, Chi-square 0.62, $d f=1$
Location of Aneurysm

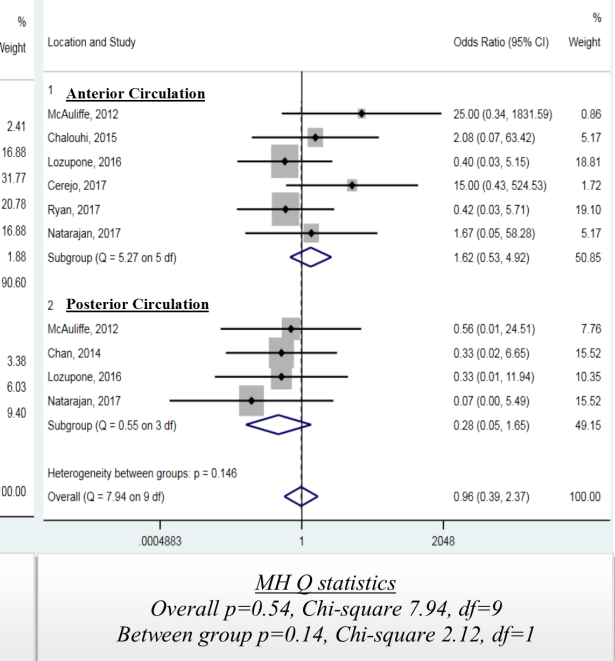



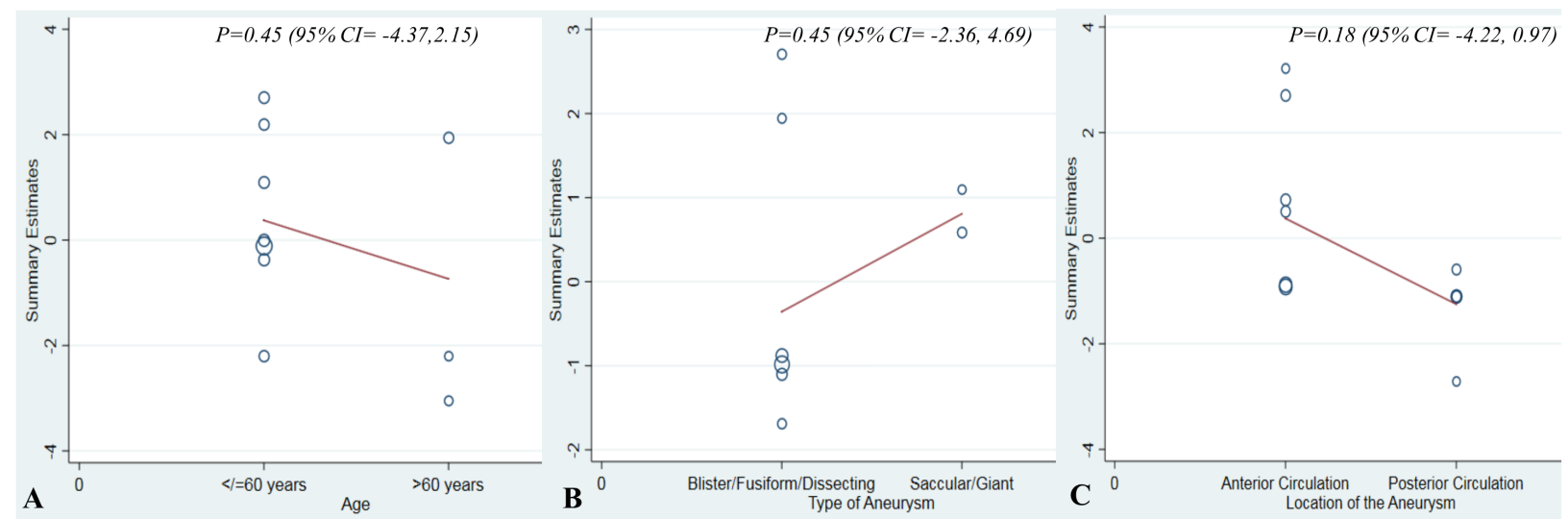

\begin{abstract}
A
\end{abstract}
$</=60$ years Age $>60$ years B Type of Aneurysm
Tyccen 


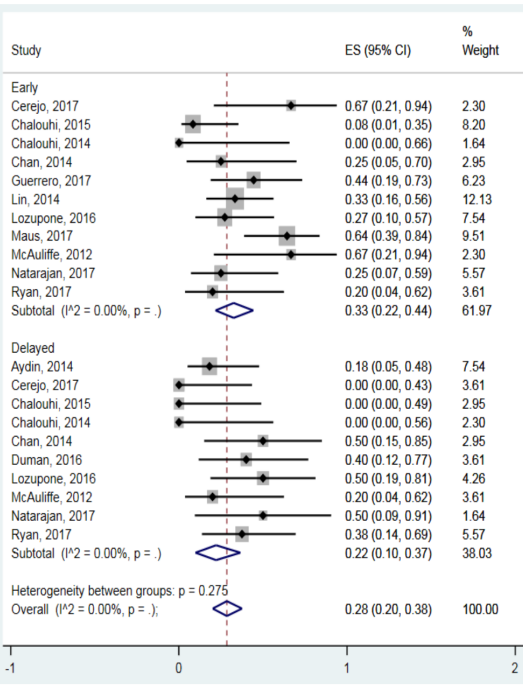

Overall Complication

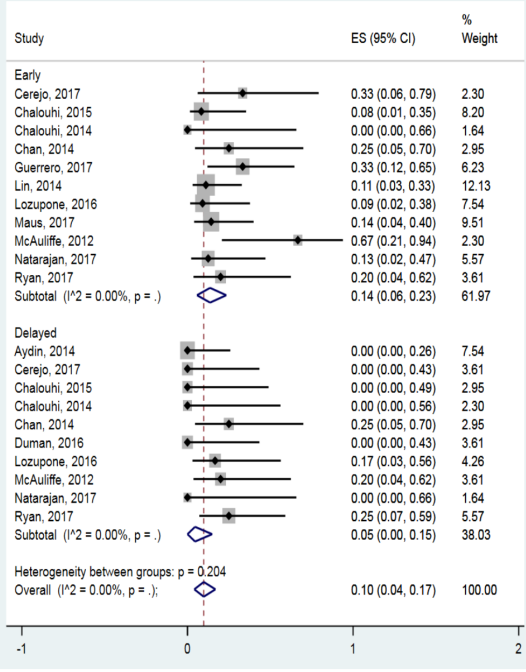

Hemorrhage

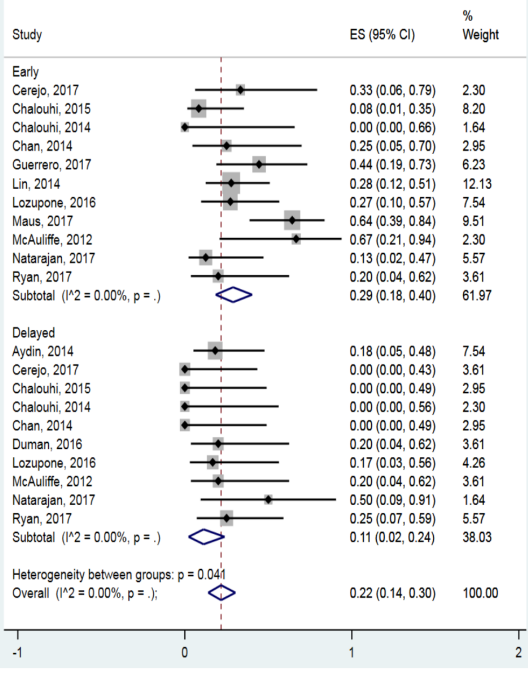

Stroke / Death 


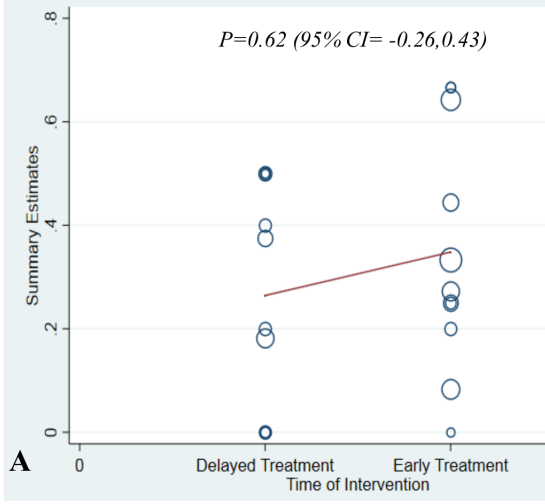

Overall Complication

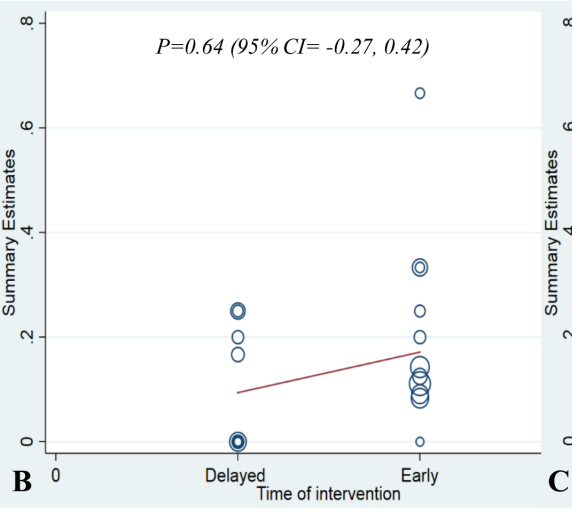

Hemorrhage

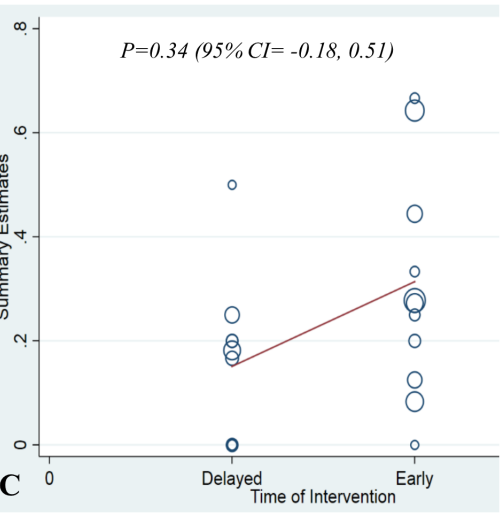

Stroke / Death 

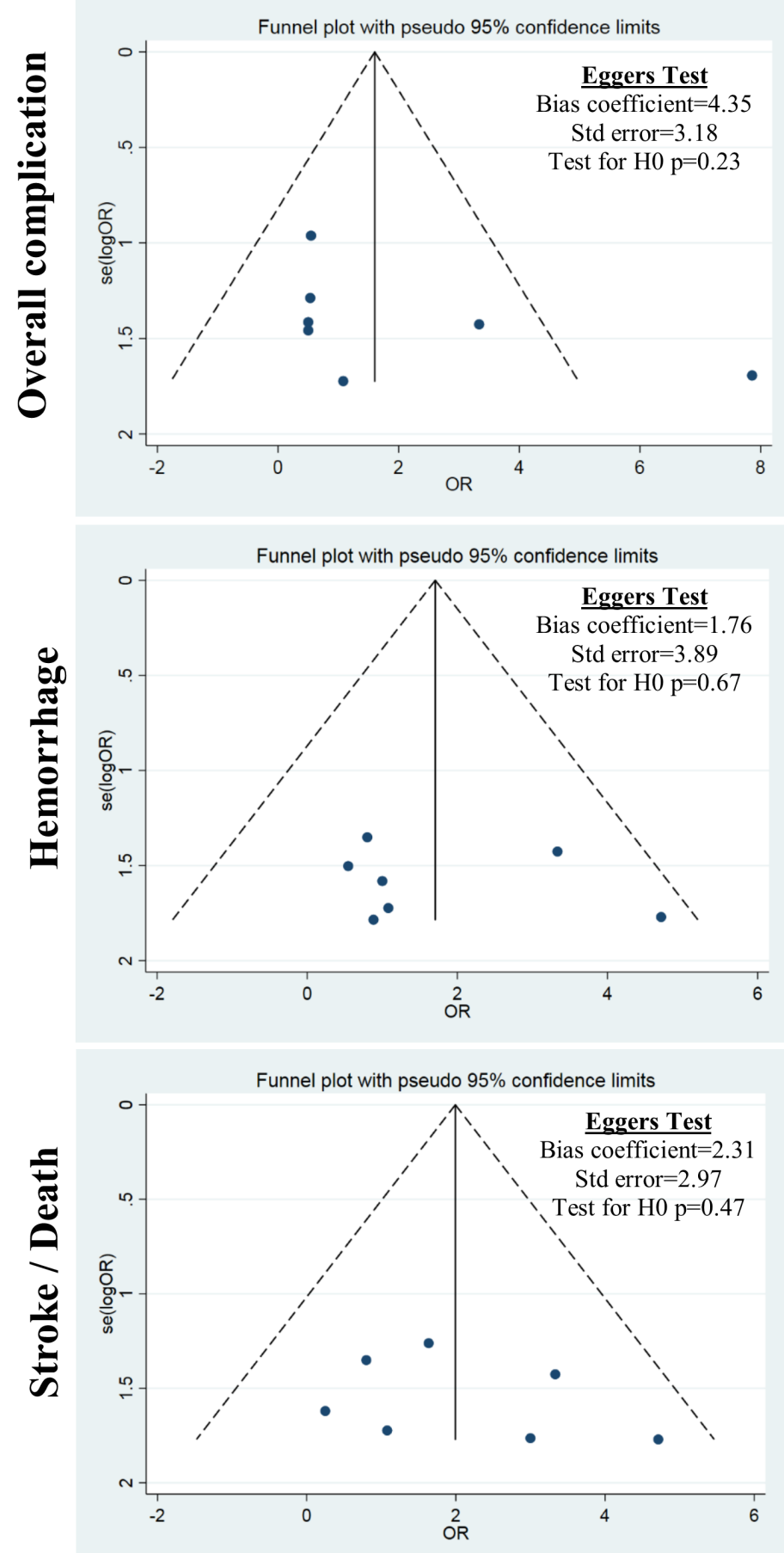


\section{ABBREVIATIONS}

SAH: subarachnoid hemorrhage

ISAT: International subarachnoid aneurysm trial

BRAT: Barrow Ruptured Aneurysm Trial

NHLBI: National Heart, Lung, and Blood Institute

IPD: Individual Participant Data

PED: Pipeline Embolization Device

PRISMA: Preferred Reporting Items for Systematic Reviews and Meta-analysis 